\title{
BMJ Open Motivation of Dutch high school students from various backgrounds for applying to study medicine: a qualitative study
}

Anouk Wouters, ${ }^{1,2}$ Gerda Croiset, ${ }^{1,2}$ Ulviye Isik, ${ }^{1,2}$ Rashmi A Kusurkar ${ }^{1,2}$

To cite: Wouters A, Croiset G, Isik U, et al. Motivation of Dutch high school students from various backgrounds for applying to study medicine: a qualitative study. BMJ Open 2017;7:e014779. doi:10.1136/ bmjopen-2016-014779

- Prepublication history and additional material are available. To view these files please visit the journal online (http://dx.doi. org/10.1136/bmjopen-2016014779).

Received 24 October 2016 Revised 21 March 2017 Accepted 21 April 2017

\section{CrossMark}

${ }^{1}$ VUmc School of Medical Sciences, Research in Education, Amsterdam, The Netherlands

${ }^{2}$ LEARN! Research Institute for Learning and Education, Faculty of Psychology and Education, VU University Amsterdam, Amsterdam, The Netherlands

Correspondence to

Anouk Wouters; a.wouters@ vumc.nl

\section{ABSTRACT}

Objective To explore high school students' motivation for applying to study medicine and the factors that influence this. To find explanations for under-representation of minority students in medical education, descriptions of motivation of students with different background characteristics were compared.

Design Qualitative phenomenological study using semistructured one-on-one interviews.

Setting One predominantly white and one mixed high school in a large multicultural city in the Netherlands. The study was conducted in March-December 2015.

Participants Twenty-four high school students, purposively sampled for demographic characteristics. Methods The analysis consisted of the coding of data using a template based on the motivation types (autonomous and controlled motivation) described by self-determination theory and open coding for factors that influence motivation.

Results The main reasons for pursuing a medical career pertained to autonomous motivation (interest in science and helping people), but controlled motivation (eg, parental pressure, prestige) was also mentioned. Experiences with healthcare and patients positively influenced students' autonomous motivation and served as a reality check for students' expectations. Having to go through a selection process was an important demotivating factor, but did not prevent most students from applying. Having medical professionals in their network also sparked students' interest, while facilitating easier access to healthcare experiences. Conclusions The findings showed a complex interplay between healthcare experiences, growing up in a medical family, selection processes and motivation. Healthcare experiences, often one of the selection criteria, help students to form autonomous motivation for studying medicine. However, such experiences as well as support in the selection process seem unequally accessible to students. As a result, under-represented students' motivation decreases. Medical schools should be aware of this and could create opportunities to acquire healthcare experiences. High schools could incorporate internships as part of their study counselling programmes and offer tailor-made guidance to each individual student.

\section{INTRODUCTION}

Concerns exist that the medical profession insufficiently reflects the society it serves. ${ }^{1}$

\section{Strengths and limitations of this study}

- This study is one of the few that investigates motivation for studying medicine among those who are still in the process of making a study choice.

- The qualitative design and the use of selfdetermination theory as a theoretical framework yielded a rich data collection and allowed for exploration of the complex mechanism underlying motivation for the medical study, including the role of selection processes.

- Having members with various backgrounds in the research team strengthened the validity and reliability of the data analysis.

- Because the current study included students from urban high schools only, factors which are specific for students from more rural areas may not have been identified.

- Parents were not included in this study; therefore, their influence on students' motivation for studying medicine remains to be investigated.

Debates increasingly focus on the disadvantage of under-represented socio-demographic groups due to the use of selection processes to decide who gets admitted to medical programmes. Under-representation of ethnic minority students, ${ }^{2}{ }^{3}$ students without a medical family background, ${ }^{4-6}$ students who are the first in their family to go to a university, ${ }^{58}$ lower socioeconomic status (SES) students $^{359}$ and males ${ }^{9}{ }^{10}$ in the medical student population can, to some extent, be ascribed to biased selection processes. ${ }^{11-24}$ However, under-representation is not always due to a bias in selection processes ${ }^{4614162125-27}$ and widening-access efforts targeting selection bias have been till date only moderately successful in resolving disparities. ${ }^{15} 21222428$ This stresses the need for other measures. A self-selection effect, which refers to students deciding whether to apply based on the information they have, for example, about the selection process, ${ }^{1629}$ has been suggested 
as another possible reason for under-representation. Indeed, certain groups of students are under-represented in the medical applicant pool, such as males, ${ }^{9}{ }^{21}$ lower SES applicants, ${ }^{9} 11^{113}$ applicants from lower educational backgrounds ${ }^{11}$ and ethnic minority students. ${ }^{9}{ }^{30}$ Various reasons have been suggested for self-selection by under-represented groups. These entail lower awareness about selection processes as a result of attending a less well-informed school, ${ }^{2} 31$ a lack of parental and peer support owing to negative views on academic excellence ${ }^{232}$ and a lack of access to the preparatory activities for selection processes (such as healthcare experiences). ${ }^{2} 31$ As a result, students' motivation for studying medicine is likely to be negatively affected. The current study is an attempt to shed light on how high school students, that is, the medical school applicant pool, decide whether to apply to study medicine and whether the presence of selection processes influences their motivation. The findings may provide clues to whether the under-representation of certain students is a result of students refraining from applying because of reduced motivation induced by the presence of selection processes.

In line with Deci and Ryan's self-determination theory (SDT), ${ }^{33} 34$ students' motivation for applying to medical school can be based on genuine interest (intrinsic motivation) and positive valuation of the medical profession (identified regulation), which together are defined as autonomous motivation. The choice can also be driven by internal pressures, such as feelings of guilt (introjected regulation), or external pressures or rewards (external regulation), which together are defined as controlled motivation. Research has indicated that autonomous motivation is the most desirable type of motivation and important for students' achievement outcomes and positive well-being of students. ${ }^{35-40}$ Moreover, students with autonomous motivation are more likely to deliver autonomy-supportive and better patient care. ${ }^{41}$ The fulfilment of three basic psychological needs-autonomy (making one's own choices), competence (feeling capable of doing something) and relatedness (sense of belonging to others) - fosters autonomous motivation. ${ }^{34} 40$

The motivation for pursuing a medical career is well investigated. Students generally have multiple reasons for pursuing a medical career. The reasons are mainly altruistic (eg, helping patients, serving the society), ${ }^{781042-55}$ but also related to interest in science, ${ }^{810424445505254}$ vocation, ${ }^{4748}$ career opportunities, ${ }^{42444547485255}$ highincome, ${ }^{78424547-5055}$ prestige ${ }^{7843-45474855}$ and family expectations or pressure. ${ }^{4349556}$ Factors influencing the choice to study medicine are work experience with patients, ${ }^{42}$ having a medical family background, ${ }^{45} 4748$ experiences with illness in the close environment, ${ }^{45} 484952$ previous school achievements, ${ }^{47}{ }^{49}$ receiving support, ${ }^{49} 50$ positive role models ${ }^{49}{ }^{50}$ and TV. ${ }^{50}$ Demotivating factors have also been investigated and are related to financial concerns, ${ }^{2} 10305457$ characteristics of the profession (eg, lack of independence, work-life balance, unemployment), ${ }^{2304649545758}$ discouragement by others, ${ }^{2304957}$ bad publicity, ${ }^{46}$ study characteristics (eg, length of study), ${ }^{2103058}$ the use of selection processes, ${ }^{2} 103057$ interest in other areas of study/careers, ${ }^{2} 30$ a lack of support ${ }^{2}{ }^{49}$ and a lack of self-confidence. ${ }^{49}$ How these factors influence the different types of motivation and one another is unknown. Knowledge about the mechanisms and the interplay between factors can help study counsellors to stimulate a choice based on autonomous motivation. This can enhance student performance and well-being.

To understand the complex mechanisms, students' background characteristics, such as gender, SES and ethnic and parental background, need to be taken into account as well. For example, female $e^{7845474859}$ and ethnic majority students ${ }^{32}$ report more altruistic motives, while male ${ }^{4547459}$ and low SES students ${ }^{32}$ report more extrinsic motives. This disparity has consequences for study choice counselling and for assessment of motivation during selection processes.

It has been argued that for purposes of widening access, interventions should target under-represented groups to encourage them to apply to medical school. ${ }^{9}$ To be able to do this effectively, there needs to be a greater understanding about the factors that encourage or discourage students to apply to medical school. ${ }^{46}$ Most studies addressing the motivation for studying medicine have gathered information retrospectively from medical students ${ }^{584-45} 49515256$ or even physicians. ${ }^{47}$ Only few investigated this among high school students ${ }^{2} 1032465055$ or undergraduate students ${ }^{557}$ during their study choice or application process. Moreover, a qualitative study can help in understanding the complex interplay between the factors that are involved. We had the opportunity to study this in a setting where admission is changing from lottery- based to selection-based. In the lottery, all applicants had a chance to be admitted and the chances of admission increased parallel to applicants' pre-university grade point average, while in selection only the top-ranked applicants based on academic and non-academic selection criteria are admitted. This policy change has profound consequences for those who are interested in studying medicine, which makes it an interesting context for research.

The following research questions guided our study:

1. What types of motivation do high school students have for applying to medical school and how can these motivations be classified according to SDT?

2. Which factors play a role in reaching these different types of motivation? and

3. Do factors playing a role differ for students with different background characteristics?

\section{METHODS}

Because the mechanisms and the interplay between the factors that are involved are unknown, we chose a qualitative design. We drew upon a constructivist point of view, in which knowledge is considered socially constructed by the people involved in the research process and our 
reality is viewed as constructed by our social and individual contexts. ${ }^{60}$ We took a phenomenological approach, and the aim was to understand the complex world from the point of view of those who live it, that is, the subjective experiences of high school students during their study choice process. ${ }^{6061}$ We conducted interviews because interaction between the researcher and the researched is crucial to come to an understanding of meanings. ${ }^{62}$ Multiple perspectives and perceptions of a variety of people were sought to enable better interpretations of the meanings of the phenomenon under study. We used the COnsolidated criteria for REporting Qualitative research (COREQ) checklist for reporting qualitative research for the assurance of good quality (see online supplementary file 1 ).$^{63}$

\section{Setting}

In the Netherlands, high school students graduating from 6-year pre-university education with science subjects are eligible for entry into medical programmes. Students choose these subjects in the third grade. At the time this study was conducted, March-December 2015, the admissions system was in the process of changing from lottery-based and selection-based admissions to only selection-based admissions from 2017. The lottery procedure was weighted for students' pre-university grade point average, and students' likelihood of admission increased with a higher grade point average. In addition, applicants could participate in a selection process by applying halfway through their final year; for the lottery, students could apply until nearly the end of the final year. The proportion of the students that medical schools were allowed to admit through selection processes increased from $50 \%$ to $100 \%$ through the years. Annually, nearly 2800 students can enrol in medical programmes in the Netherlands.

\section{Participants}

We interviewed a purposive sample of high school students and study counsellors from two schools in Amsterdam (see table 1), as we were interested in a variety of viewpoints and experiences. One school is located in the part of the city with the highest average disposable income per household and predominantly white (school A), while the other school is located in a more ethnically and culturally diverse part of the city, where the average disposable income per household is substantially lower (http://www.ois.amsterdam.nl/feiten-en-cijfers/ stadsdelen) (school B). Because students usually go to a school close to their homes, we felt this approach sufficed in yielding the desired diverse study sample in terms of students' background characteristics. To obtain the views and experiences of students who are in different phases of their study choice process, we interviewed third-year to sixth-year high school students who (once) were interested in studying medicine.

\section{Procedure}

Directors of two high schools were approached and invited to participate in this research. First, in 
semistructured interviews with the study counsellors of the high schools that were involved in the guidance of the students, we gathered information about which elements they identified in students' study choice processes (eg, parental influence), which yielded topics to address in the subsequent interviews with students. These interviews also served to gather information about the composition of the schools' student populations and the way in which study choice counselling was organised. The study counsellors purposively recruited students they knew considered or had considered studying medicine for one-time participation in the study. All students participated and none dropped out of the study. The one-on-one interviews were conducted by AW at the two high schools and lasted between 31 and $52 \mathrm{~min}$. At the beginning of the interview, AW introduced herself and explained the purpose of the study. At the end of the interview, students were asked to draw a graph showing how their motivation had increased and/or decreased over time from the moment they considered medicine as a possible study choice and to write down when and why changes occurred. This graph served as a summary and stimulated the recollection of further important aspects. Interviews were semistructured and were altered based on arising topics in earlier interviews in an iterative process and adjusted to the type of participant (study counsellor or student) and to the expected study choice phase of students based on the grade they were in. See box for the interview guide used in the interviews with the students. Interviews were audiotaped and transcribed verbatim. All transcriptions were checked for accuracy. A summary of each interview was presented to the respective interviewee as a form of member checking. Students either approved their summary or provided no response. When sufficiency (to answer the research questions) and data saturation were reached, no more interviews were conducted.

\section{Data analysis}

AW read and reread and familiarised herself with the data. AW coded all interviews using ATLAS.ti. The first interview was coded together with a second researcher, UI. Further in the coding process, another four interviews were independently coded by AW and UI. Whenever there were differences in coding, these were discussed until consensus was reached. Because there were very few differences and they mainly concerned the phrasing of new codes, AW coded the remaining interviews. We analysed all data using SDT as a theoretical framework. The different motivation types (intrinsic motivation, identified regulation, introjected regulation and external regulation) formed the basis for a coding template for students' reasons to pursue a medical career. ${ }^{64}$ The quotations were first identified as expressions of a particular motivation type (eg, intrinsic motivation) and further categorised (eg, scientific interest). Open coding was conducted to identify the factors that influenced students' motivation in a positive or negative manner. ${ }^{65}$
Box Interview guide used in the interviews with the students

Q1: Study choice process

Where are you in your study choice process?

- What are the considerations you made/make? Which doubts have you had/do you have? Why?

- What kind of information do you gather to make a study choice? How did you acquire this information?

Which source of information is/was most important to you?

From the moment you considered medicine as a possible study choice:

Q2.1: Reasons for choosing medicine

- What started your desire to study medicine?

What other reasons inspired you to study medicine?

Have these reasons, or their importance, changed? Why?

- Which other factors have influenced your choice? Examples: student (characteristics, illness), home situation (parents, illness in family), school (guidance, peers), friends, culture, university (information days, selection)

What is the most important reason for you to study medicine?

Q2.2: Possible reasons for refraining from choosing the medical study

- What would be reasons for you to move away from your choice for medical study?

Q3: Applying for medical study (selection)

- What do you know about selection? Have you seen the criteria? (How) did/do you prepare? What are your expectations of the procedure? How do you estimate your chances of success? Do the criteria affect your desire to study medicine? Or do they have any other effects?

Q4: Facilitators/barriers during study choice process

Which factors made/make it difficult to make a study choice?

Which factors decrease(d) your motivation for the medical study?

Which factors made/make it easier to make a study choice?

- Which factors increase(d) your motivation for the medical study?

Q5: Motivation graph

- Can you draw a graph which represents your motivation for studying medicine from the moment you considered medicine as a possible study choice?

Closing question

-What has not been discussed but is deemed relevant by the student?

Factors identified in quotations were first categorised as factors of influence, next (if possible) as positively or negatively influencing factors, and finally according to the topic (eg, selection processes) and subcategory (eg, CV building). Quotations that contained expressions of students' basic psychological needs (ie, autonomy, competence and relatedness) were also coded. The findings were discussed and agreed upon by the full research team. Reflexivity is a critical aspect in the analytical process. We acknowledge that while using SDT as a theoretical framework for our analysis allows for a deeper understanding of students' motivation for studying medicine, this particular focus may also cause us to overlook other relevant aspects. We tried to keep this to a minimum by keeping notes, 'memos', of findings outside our theoretical framework that seemed relevant for understanding the mechanisms. 
Table 2 Distribution of participating students by high school, gender and grade

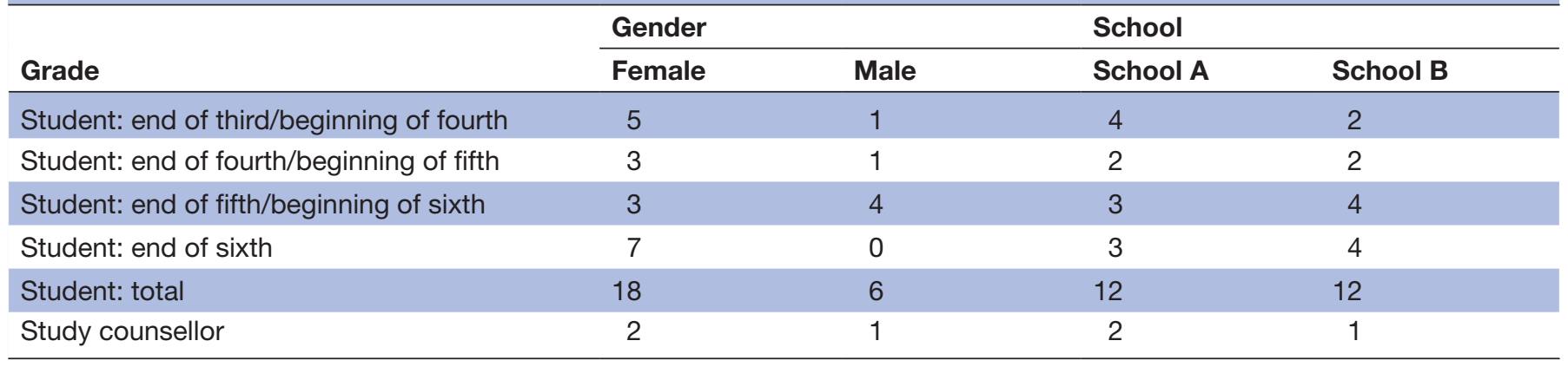

\section{Ethical considerations}

Participation was voluntary. We provided participants with information about the purpose of the study and the handling of personal data, after which they signed an informed consent form. The audio-recordings and interview transcripts did not contain identifying information about the participants, have been stored with anonymous descriptions and are accessible only to the principal researcher. Students received a $€ 15$ gift card for their participation. This study has been approved by the Netherlands Association for Medical Education Ethical Review Board (NVMO-ERB), dossier number 408.

\section{RESULTS}

Three study counsellors and 24 students participated in this study. Tables 2 and 3 provide overviews of the distribution of participants, and the identified categories and subcategories, respectively.

\section{Motivation for applying to medical school}

Both subtypes of autonomous motivation were addressed to a great extent by the students. Intrinsic motivation was seen in a (scientific) interest in medicine and the working of the human body and altruistic reasons (the desire to help patients). The desire to help people was more prominent among females than among males. Students stressed the importance of choosing an area of study they find interesting.

[The most important reason is] that I am interested in the human body, in combination with working with people. [...] This has actually always been most important. I believe that when you choose a study, interest, wanting to learn, is most important. You can say, then this, then that, then you make a lot of money or something, but you have to persevere in your studies, which can only be done when you are interested. (S13, female, school A)

With regard to identified regulation, students expressed that they were interested in studying medicine because they value and acknowledge the importance of medical study and the medical profession.
The fact that my sister was in the hospital played a big role. It was the doctors who cured her. It instigates admiration and then you want to do it yourself. (S19, female, school B)

Some expressions of external regulations and some expressions of introjected regulations could also be identified. External regulations related to obtaining a degree, job perspectives, parental pressure and expectations, prestige, high salary and working conditions (atmosphere, action and variety).

But on the other hand, I think, it's my own life. But it is easier to conform to your parents' wishes, to get rid of the nagging. And also, it's a little like, it doesn't feel right to do something your parents disapprove of. (S7, female, school A)

Actually, what everyone secretly thinks, prestige. Being a doctor is highly regarded. I think that's one of the main reasons for the recent popularity of the study. Many people want prestige in society. I am not going to be a hypocrite and say, not me. (S16, male, school A)

Introjected regulations seemed related to maintaining self-worth and one's image. One of the reasons was that students felt they had to stick to their decision to study medicine, as that is what they had always wanted. Another reason is that students had a tendency to comply with the views others had of them, or prove themselves to others, which was mainly seen among female students.

My friends know me well, you know. And they are just being honest, like, I don't really see this for you. [...] You know, they ... see, like you're a bit lazy, things that really matter for choosing a study. (S3, female, school B)

In the case of the following student, this was related to having an ethnic minority background:

Because I actually really liked it, but I thought, if I am really going to do it, it will be like ... Maybe people will see that it doesn't matter if you are a girl of ethnic minority origin. (S3, female, school B) 

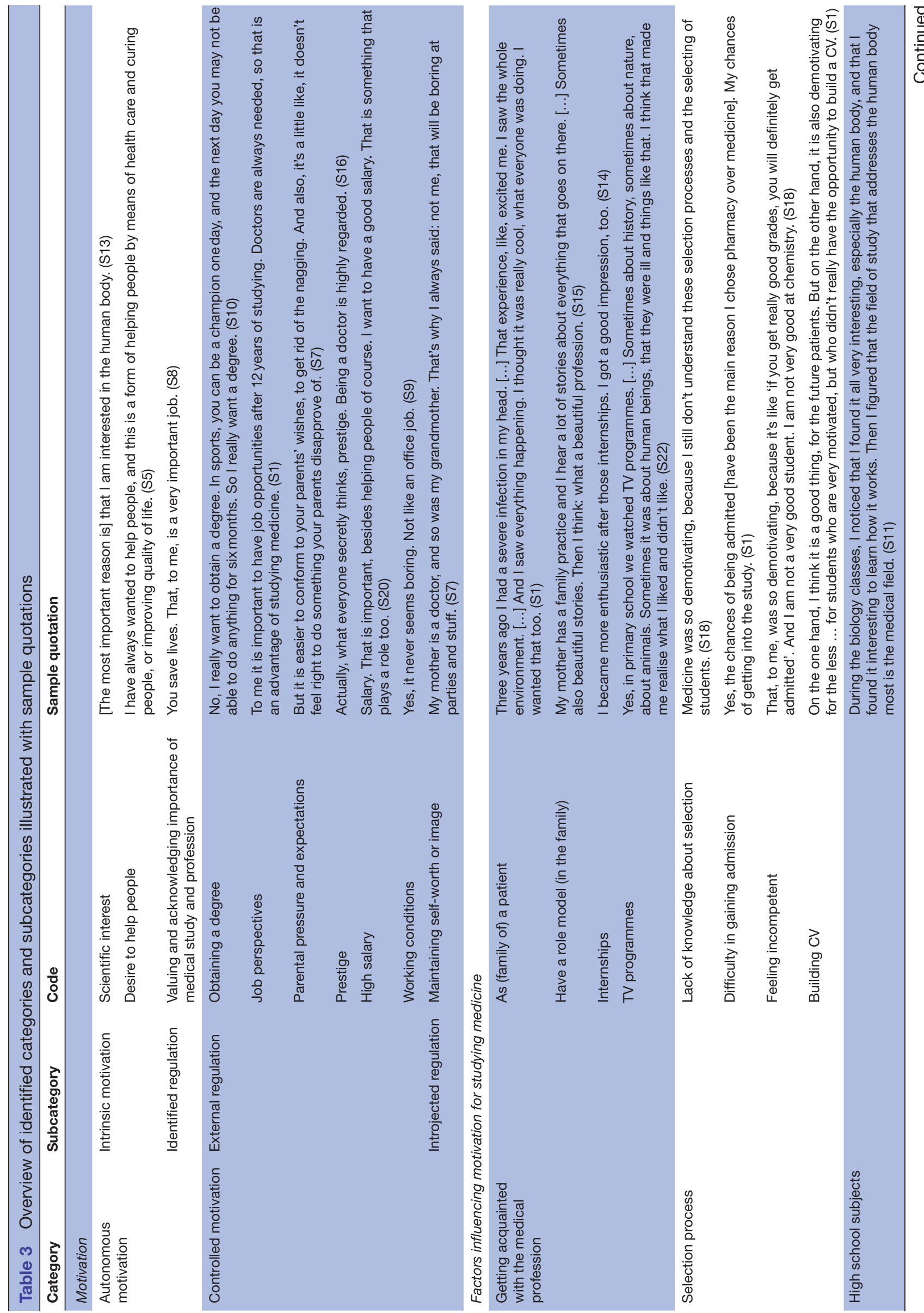


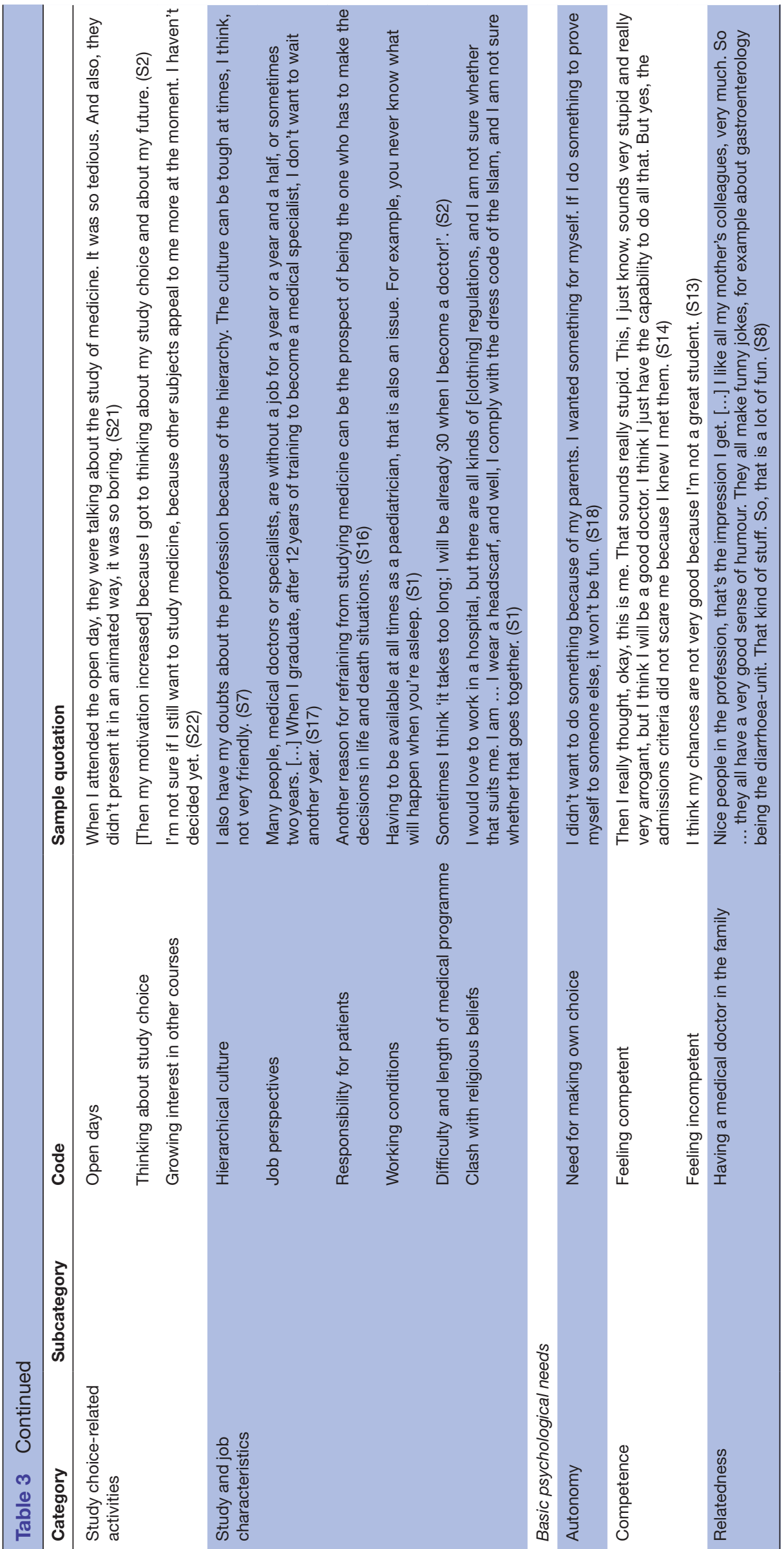


Main factors influencing students' motivation for studying medicine

\section{Getting acquainted with the medical profession}

The most prominent factor that influenced students' autonomous motivation and strength of motivation was experiencing or gaining knowledge about the medical profession. This was reached when students themselves or relatives had been patients or when students had come into contact with the medical profession due to having medical professionals in the family or other role models, which led them to realise the importance of the medical profession and elicited their interest in medicine.

Well, that thing with my cousin, that made quite an impact. It really made me see how much doctors do.

(S9, female, school A)

A general belief was that having a medical doctor as a parent made it easier to gain information about the medical profession, as well as getting access to internships in healthcare. However, while several school A students had a medical doctor parent, none of the school B students did. Internships were considered most valuable for getting acquainted with the medical profession, and gaining such experiences was the main factor that had a positive influence on autonomous motivation for studying medicine. Students experienced how doctors make diagnoses and treat diseases, which often confirmed their interest in medicine.

The internship was so much fun. [...] one woman had a lot of complaints; she had many illnesses, let's put it that way. [...] I had to keep her company. She told me many things about what it's like, so I had to really listen, pay attention, so she can talk to someone and get things off her chest. [...] It was just nice; listening to someone, helping someone; it gave me a good feeling. After that meeting [...] I thought, that was actually nice. Then I thought, I really want to do something to help people. (S18, female, school B)

Getting acquainted with the medical profession through medical professionals and internships also served as a reality check, which reduced their autonomous motivation. Learning about the downsides made some female students realise that their image of the profession was inaccurate and that they had romanticised the aspects they valued and liked about the profession. Students considered whether the information they had gathered about the profession matched their own preferences and perceived capabilities.

Yes, that is partly why I lost interest in medicine. I thought, when you, as a doctor, hear such things, you must be able to cope with not everyone being healthy, and that anything can happen. That makes me wonder, can I handle that?' (S22, female, school B)

For some female students, TV programmes (reality shows and documentaries) also played a role. While reality shows elicited autonomous motivation, popular TV series, such as Grey's Anatomy, made students aware of the 'coolness' of the medical profession.

Yes, in primary school we watched TV programmes. [...] Sometimes about history, sometimes about nature, about animals. Sometimes it was about human beings, that they were ill and things like that. I think that made me realise what I liked and didn't like. (S22, female, school B)

\section{Selection}

Overall, many students appeared to have little knowledge about the admissions process. There seemed to be differences between students from the two schools. Students from school B in particular lacked knowledge about the admissions process. This was true even for those in their final year of high school. They were either unaware of the change from the lottery to selection or what selection entailed.

While males mentioned that selection had no effect on their motivation, for a number of females it had a significant impact; one female student even refrained from applying due to the presence of a selection process. Their motivation decreased due to the difficulty in gaining admission to medical programmes and students lost hope of being successful in the selection process because they felt insecure about their competence, particularly compared with other applicants.

Sometimes [my motivation] was higher, sometimes lower. It was always high, but sometimes I thought, I always wanted to help people, and this of course is very much helping people by means of health and by means of curing people, enhancing quality of life. But at some point, at age 12, I knew how difficult it is to become a doctor. Then I thought, I need an alternative. (S5, female, school A)

Building a CV appeared to be the aspect of the selection process with the most demotivating effect on students. There seemed to be differences in the experiences of the students from the two schools with regard to building their $\mathrm{CV}$ and their chances of success in the selection process. Some students from school A thought that attending their school would be an advantage in the selection process because the education was perceived to be superior to that of other schools. Moreover, some students from school A reported that they had people in their network who could help them prepare for the selection process because of their experience as a student, medical professional or because they were involved in the selection process at a medical school. In addition, many of those students had easy access to healthcare-related activities for CV-building purposes. One student from school B expressed that she heard that applicants with a foreign last name would be discriminated against. 


\section{High school subjects}

Studying high school subjects related to medicine, seeing how these relate with practice and finding out how the human body works boosted students' interest and enjoyment.

During the biology classes, I noticed that I found it all very interesting, especially the human body, and that I found it interesting to learn how it works. Then I figured that the field of study that addresses the human body most is the medical field. (S16, male, school A)

\section{Study choice-related activities}

Attending open days (especially student-for-a-day programmes) and actively thinking about their career choice generally increased students' strength of motivation. Open days could also have a demotivating effect when the talks were boring. Another common factor that was mentioned as having a negative influence on motivation for studying medicine was a growing interest in other courses.

'When I attended the open day, they were talking about the study of medicine. It was so tedious. And also, they didn't present it in an animated way, it was so boring. If I compare it to pharmaceutical sciences ... That is not really something I aspire to study, but they presented it in a much nicer way. It came across as more interesting than the medical field, while I actually want to study medicine. (S21, female, school B)

\section{Study and job characteristics}

Some aspects of medical education and the medical profession made students doubt their study choice, such as the hierarchical culture, job perspectives, responsibility for the life and death of patients, working conditions (eg, working hours, work-life balance) and the difficulty and length of medical programmes. There was one factor that particularly played a role for female students from school B. They expected a clash with their religious beliefs (eg, regarding dress code, practising skills on students of the opposite sex).

Yes, what I hear a lot lately is that the job opportunities after graduation are very limited. That is really something that holds me back a little. Otherwise I would definitely have chosen medicine, I'm sure about that. (S20, male, school B)

I would love to work in a hospital, but there are all kinds of [clothing] regulations, and I am not sure whether that suits me. I am ... I wear a headscarf, and well, I comply with the dress code of the Islam, and I am not sure whether that goes together. (S1, female, school B)

These aspects did not seem to prevent most students from choosing medicine, which was explicitly expressed by students.

\section{Basic psychological needs}

\section{Autonomy}

Students described how they wanted to feel autonomous in making their career choice. Although they mentioned that parents' and, to a lesser extent, friends' opinions were important, they stressed the need to do what they want. Many students pointed out that they expected it to be difficult to remain satisfied with their professional life when their career choice would be driven by what others want instead of what they want. Students from school A expressed this more firmly than students from school B.

I didn't want to do something because of my parents. I wanted something for myself. If I do something to prove myself to someone else, it won't be fun. (S18, male, school A)

Parental influence was reported by the study counsellors as one of the most important factors influencing students' study choices. Parents seem to stimulate their children to make their own choice, although at the same time strongly conveying their expectations to their children. Parents may have a stronger influence than is perceived by students, and students' need for autonomy may therefore be less satisfied than they perceive it to be.

So far, my father ranked medicine number one, but I don't think this had an influence on me, or that I wanted to study medicine because of him. I'm doubting a little, $[\ldots]$, whether I am influenced by people. (S22, female, school B)

\section{Competence}

Female students expressed feelings of (in)competence that were related to the study of medicine, the medical profession and their participation in a selection process, while both male and female students expressed the need to be challenged in their studies.

Then I really thought, okay, this is me. That sounds really stupid. This, I just know, sounds very stupid and really very arrogant, but I think I will be a good doctor. I think I just have the capability to do all that. But yes, the admissions criteria did not scare me because I knew I met them. (S14, female, school A)

I found it a bit scary, the lottery and selection [...]. And I am very smart. I don't want to be arrogant. I am intelligent, but I don't have a pre-university attitude. And yes, my grades are always about 6.5 average. And yes, I thought, this doesn't quite fit ... my attitude and yes ... It was a bit scary; it made me a little insecure. (S3, female, school B)

Feelings of competence increased students' motivation for studying medicine, for example, passing a test in a school subject related to medicine.

\section{Relatedness}

Female students from school A had a positive impression of doctors as a result of having family members in the 


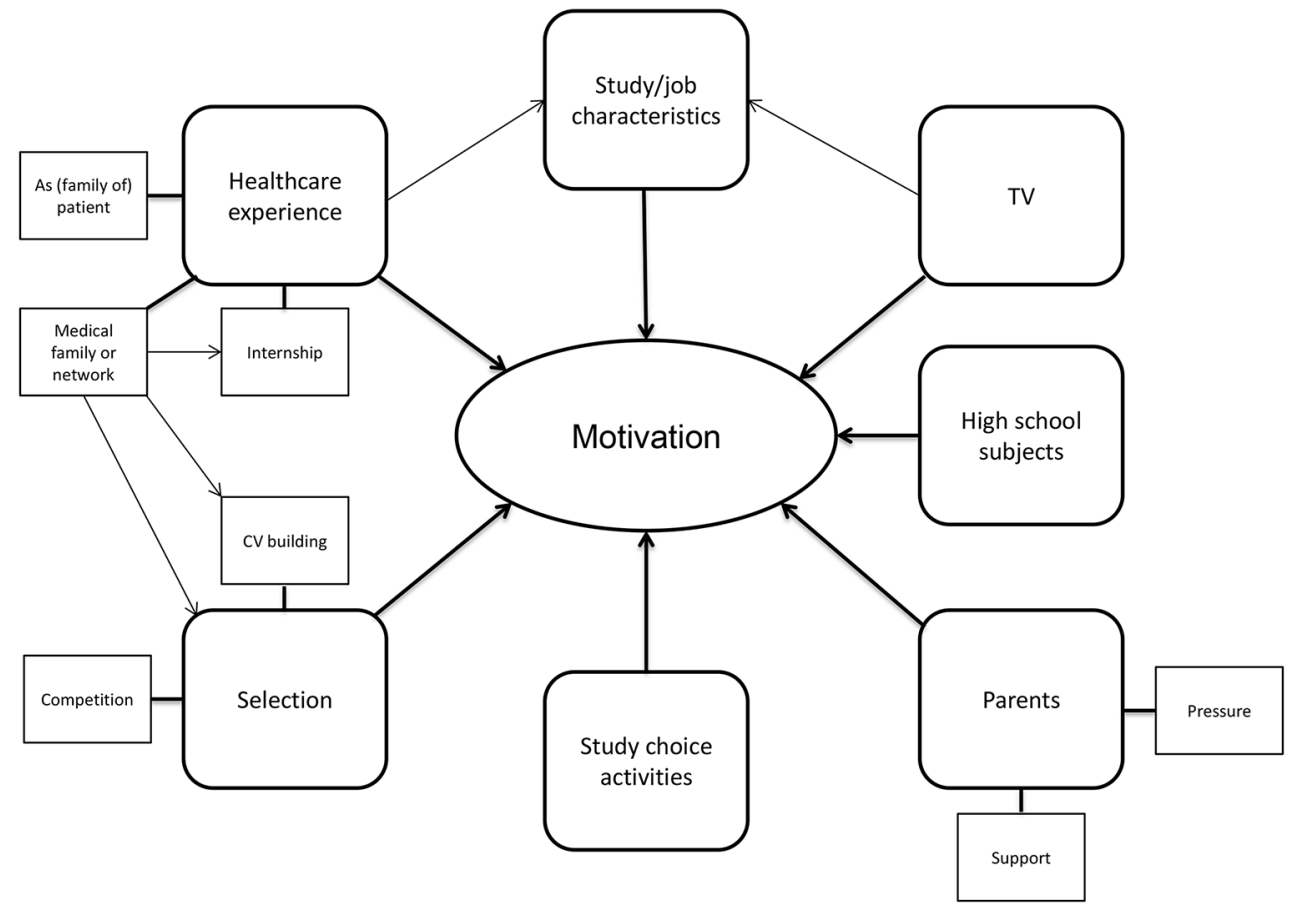

Figure 1 Overview of the mechanisms through which motivation for studying medicine is influenced according to students and the interplay between the factors.

medical profession. This gave some students the desire to belong to that professional group.

Nice people in the profession, that's the impression I get. [...] I like all my mother's colleagues, very much. So ... they all have a very good sense of humour. They all make funny jokes, for example about gastroenterology being the diarrhoea-unit. That kind of stuff. So, that is a lot of fun. (S8, female, school A)

\section{Summary}

An overview of the factors that play a role in high school students' motivation for studying medicine is provided in figure 1 . We found that students' main motivation was of the autonomous type, such as interest in science, helping others and valuing the medical profession. Controlled motivation concerned parental pressure, prestige and salary. Healthcare experiences, the presence of selection processes and having a parent in the medical field were important factors for students' study choice process and motivation, but social disparities in exposure to medicine exist.

\section{DISCUSSION}

\section{Principal findings}

Mainly autonomous motivation for studying medicine, that is, the desire to help people and a scientific interest, was reported, but controlled motivation, such as prestige, was also reported. This is in line with previously reported findings. With regard to how the motivation for studying medicine is formed and the role of selection processes in this, there appears to be a complex interplay between healthcare experiences, growing up in a medical family, the use of selection processes and motivation (see figure 1). We found exposure to healthcare to be a crucial factor impacting students' motivation. Such exposure fostered an interest in medical subjects and the desire to help others and made students value the medical profession, but it could also serve as a reality check and make students realise that they previously had unrealistic expectations. The beneficial effect of healthcare experiences with real patients on students' motivation has been reported previously. ${ }^{32}$ Moreover, the variety of factors in combination with the interplay between these factors highlights how the motivation for studying medicine is shaped depending on the individual student. Growing up in a medical family enhanced students' motivation to study medicine and provided easier access to acquiring healthcare internships and assistance in the selection process. Healthcare experience is often one of the selection criteria. This highlights an inequality in access to resources relevant for both the study choice process and the selection process related to students' background characteristics. In our study, we found that the perceived inequality could be a demotivating factor for students without a medical network. This may induce self-selection among students without such a network. This might especially be true for students who grow up with the notion that they are not fit for a university and have no doctor role models to inspire them. ${ }^{2}{ }^{32}$ As a result, the intended diversity within the student population could be compromised. The change from lottery-based admissions to selection-based admissions, as is occurring in the Netherlands, allows student diversity to be monitored to 
determine whether the use of selection processes negatively effects student diversity.

\section{Implications of the study}

Our findings provide initial insight into which areas can be addressed to help students choose a field of study based on autonomous motivation. Although most interventions aimed at widening access are focused on facilitating the access of under-represented students by stimulating the fair treatment of applicants in selection processes ${ }^{66}{ }^{67}$ it seems worthwhile to simultaneously direct efforts towards the recruitment of a diverse group of prospective applicants. Recruitment efforts need to start with guiding high school students towards a study choice based on the right information and autonomous motivation. SDT posits motivation along a continuum and this can change from the autonomous to the controlled type and vice versa. ${ }^{33} 34$ The current study shows the complexity of how motivation is formed. Each individual student is motivated by a combination of different factors. Similarly, students experience a variety of demotivating factors. These demotivating factors can 'pull' or 'push' students away from their choice to study medicine. ${ }^{68}$ A student can be pulled away from her choice because she develops interest in other subjects or because she finds that another study better suits her values (eg, religion). A student can also be pushed away from her choice because she wants to avoid negatively valenced aspects of her choice to study medicine (eg, the presence of selection processes). The interplay between motivating and demotivating factors will lead to differently formed choices for each individual student. Therefore, tailor-made guidance of high school students appears necessary. Based on the findings, we plan to create an interview guide for study counsellors to determine which factors play a role for each student. The interplay between the factors can then be explored by means of mind mapping. This way, the motivation for choosing a study can be determined and when the controlled type of motivation is dominant, the student can be stimulated to choose a study based on autonomous motivation. A similar approach could be useful for guiding medical students towards their specialty choice. Knowledge about how autonomous motivation for different specialties is formed may provide possibilities to motivate students to opt for specialties that are aligned with the changing healthcare structure and societal needs, ${ }^{69}$ such as family medicine and geriatrics.

Previous research has shown the negative impact of the lack of connections to physicians and the misconceptions of both students and parents about the medical field on under-represented students' pursuit of a medical career $^{5758}$ and there seems to be a desire for more information about the medical profession and study, and the admission processes. ${ }^{3258}$ Exposure to healthcare seems crucial in this respect. ${ }^{258}$ Both high schools and medical schools should realise that students who do not grow up in a medical family have less access to such information and activities. ${ }^{58}$ To stimulate a choice based on autonomous motivation, high schools could encourage students to consider which subjects they like in school and offer time and possibilities for internships. In addition, a programme, such as the one used at school B, in which students who are first in their family to enrol in a university are assigned a mentor relevant to their career preferences, can provide such students with information. Despite the study choice activities offered at school B, however, many of those students still seem to be disadvantaged due to a lack of medical professionals in their network.

A striking finding was that many students seemed to be poorly informed about the selection process. ${ }^{58}$ Moreover, students felt they would be less likely to succeed than their competitors because they felt that others may have more knowledge about medicine and selection processes and more resources to prepare for the selection process. Indeed, our findings indicate an inequality in this respect. Under-represented students' concerns about the complexity of the admissions process ${ }^{58}$ and not being able to compete with other applicants have been reported previously. ${ }^{57}$ When medical schools wish to incorporate healthcare experiences as one of their selection criteria, they should acknowledge the unequal access to such experiences among high school students. For those who lack the opportunity of gaining healthcare experiences through their own network, medical schools could facilitate this. Furthermore, considering that some students have access to more information about the selection process through their network, selection committees should be as transparent as possible about their process. 454952

\section{Strengths and weaknesses of the study}

The qualitative design allowed the exploration of the complex mechanisms underlying students' motivation for studying medicine and more specifically the role of selection processes. The use of SDT as a theoretical framework was helpful in understanding how autonomous motivation, the most desirable type, is formed. Having members with various backgrounds on the research team strengthened the validity and reliability of the data analysis. Using interviews with study counsellors, in addition to findings from previous literature, to generate topics for the student interviews, enabled us to touch upon more relevant factors to answer our research questions. Moreover, the timeline that was provided to the students at the end of the interviews yielded additional information in some cases.

Our study has several limitations. We only included students from urban high schools. Other factors could play a role in the motivation of students from more rural areas. However, our findings are in line with previously reported findings. Therefore, we expect that the mechanisms can be generalised to a larger student population. Further research is required to test this hypothesis. In addition, the influence of parents on students' motivation for studying medicine was rather unclear. The study 
counsellors' and students' perceptions with this regard seemed to differ. Including parents in the study might have provided more evidence about their role in students' study choice process.

\section{Strengths and weaknesses in relation with other studies}

This study is one of the few that investigates the motivation for studying medicine among those who are still in the process of making a study choice. In addition, the qualitative design yielded richer data on motivation and factors that influence motivation than the quantitative surveys used in most previous studies. This enabled the investigation of the interplay between the factors involved. We investigated the mechanisms while acknowledging the importance of the qualitatively different types of motivation; therefore, our study adds a new dimension to the previous findings.

\section{Future research}

The mechanisms for the interplay between healthcare experiences, growing up in a medical family, the presence of selection processes and motivation have been hypothesised, but still require quantitative testing on a larger scale. One potential next step would be to validate the model in different countries and cultures. In addition, in this explorative study we found indications for differences and inequalities between students due to their backgrounds. In future research, the findings with regard to the (formation of the) different types of motivation for studying medicine and the extent to which the identified factors discourage students from applying could be compared for students with different background characteristics. Research could also focus on which types of motivation mainly occur in which cultural settings to identify the optimal setting for fostering students' autonomous motivation for studying medicine.

Correction notice This paper has been amended since it was published Online First. Owing to a scripting error, some of the publisher names in the references were replaced with 'BMJ Publishing Group'. This only affected the full text version, not the PDF. We have since corrected theseerrors and the correct publishers have been inserted into the references.

Acknowledgements The authors are very grateful to the directors of the two high schools for their cooperation in their research and to the students and study counsellors for their participation in this study.

Contributors All researchers contributed to the design of the study and interpretation of the data. AW and UI have completed courses on conducting qualitative research. AW conducted the interviews. AW and UI were responsible for the main data analysis. All researchers contributed to and approved the final manuscript.

Funding This work was partly funded by the Netherlands Federation of University Medical Centers (NFU).

Competing interests None declared.

Ethics approval This study has been approved by the Dutch Association for Medical Education Ethical Review Board (NVMO-ERB), dossier number 408.

Provenance and peer review Not commissioned; externally peer reviewed.

Data sharing statement Anonymised data set available from the main author upon request.

Open Access This is an Open Access article distributed in accordance with the Creative Commons Attribution Non Commercial (CC BY-NC 4.0) license, which permits others to distribute, remix, adapt, build upon this work non-commercially, and license their derivative works on different terms, provided the original work is properly cited and the use is non-commercial. See: http://creativecommons.org/ licenses/by-nc/4.0/

(c) Article author(s) (or their employer(s) unless otherwise stated in the text of the article) 2017. All rights reserved. No commercial use is permitted unless otherwise expressly granted.

\section{REFERENCES}

1. General Medical Council. Tomorrow's Doctors: outcomes and standards for undergraduate medical education. Manchester, UK: General Medical Council, 2009.

2. Rao V, Flores G. Why aren't there more African-American physicians? A qualitative study and exploratory inquiry of African-American students' perspectives on careers in medicine. J Natl Med Assoc 2007;99:986.

3. Young ME, Razack S, Hanson MD, et al. Calling for a broader conceptualization of diversity: surface and deep diversity in four Canadian medical schools. Acad Med 2012;87:1501-10.

4. Simmenroth-Nayda A, Görlich Y. Medical school admission test: advantages for students whose parents are medical doctors? BMC Med Educ 2015;15:81.

5. Heath C, Stoddart C, Green H. Parental backgrounds of Otago medical students. N Z Med J 2002;115:U237.

6. McManus IC, Richards P. Audit of admission to medical school: I-Acceptances and rejects. Br Med J 1984;289:1201-4.

7. Vaglum P, Wiers-Jenssen J, Ekeberg O. Motivation for medical school: the relationship to gender and specialty preferences in a nationwide sample. Med Educ 1999;33:236-42.

8. Gasiorowski J, Rudowicz E, Safranow K. Motivation towards medical career choice and future career plans of polish medical students. Adv Health Sci Educ Theory Pract 2015;20:1-17.

9. Ferguson E, James D, Yates J, et al. Predicting who applies to study medicine: implication for diversity in UK medical schools. Med Teach 2012;34:382-91.

10. Puljak L, Brnjas Kraljevic J, Barac Latas V, et al. Demographics and motives of medical school applicants in Croatia. Med Teach 2007;29:e227-34.

11. Griffin B, Hu W. The interaction of socio-economic status and gender in widening participation in medicine. Med Educ 2015;49:103-13.

12. James D, Driver L. Ethnic and sex differences in selection for admission to Nottingham University Medical School. BMJ 1999;319:351-2.

13. Laurence CO, Turnbull DA, Briggs NE, et al. Applicant characteristics and their influence on success: results from an analysis of applicants to the University of Adelaide Medical School, 2004-2007. Med J Aust 2010;192:212-6.

14. Lievens F, Patterson F, Corstjens J, et al. Widening access in selection using situational judgement tests: evidence from the UKCAT. Med Educ 2016;50:624-36.

15. Mathers J, Sitch A, Parry J. Population-based longitudinal analyses of offer likelihood in UK medical schools: 1996-2012. Med Educ 2016;50:612-23.

16. Stegers-Jager KM, Themmen AP, Cohen-Schotanus J, et al. Predicting performance: relative importance of students' background and past performance. Med Educ 2015;49:933-45.

17. O'Neill L, Vonsild MC, Wallstedt B, et al. Admission criteria and diversity in medical school. Med Educ 2013;47:557-61.

18. McManus IC, Richards $\mathrm{P}$, Winder BC et al. Medical school applicants from ethnic minority groups: identifying if and when they are disadvantaged. BMJ 1995;310:496-500.

19. McManus IC, Esmail A, Demetriou M. Factors affecting likelihood of applicants being offered a place in medical schools in the United Kingdom in 1996 and 1997: retrospective study Commentary: League tables will helpCommentary: Some legal aspects arising from the study. BMJ 1998;317:1111-7.

20. Mathers J, Sitch A, Parry J. Longitudinal assessment of the impact of the use of the UK clinical aptitude test for medical student selection. Med Educ 2016;50:1033-44.

21. Puddey IB, Mercer A, Carr SE, et al. Potential influence of selection criteria on the demographic composition of students in an australian medical school. BMC Med Educ 2011;11:1.

22. Reiter HI, Lockyer J, Ziola B, et al. For the Canadian Multiple MiniInterview Research Alliance (CaMMIRA). Should efforts in favor of medical student diversity be focused during admissions or farther upstream? Acad Med 2012;87. 
23. Steven K, Dowell J, Jackson C, et al. Fair access to medicine? Retrospective analysis of UK medical schools application data 20092012 using three measures of socioeconomic status. BMC Med Educ 2016;16:1.

24. Tiffin PA, Dowell JS, McLachlan JC. Widening access to UK medical education for under-represented socioeconomic groups: modelling the impact of the UKCAT in the 2009 cohort. BMJ 2012;344:e1805

25. Kelly ME, Dowell J, Husbands A, et al. The fairness, predictive validity and acceptability of multiple mini interview in an internationally diverse student population- a mixed methods study. BMC Med Educ 2014:14:1.

26. Jerant A, Fancher T, Fenton JJ, et al. How medical school applicant race, ethnicity, and socioeconomic status relate to multiple miniinterview-based admissions outcomes: findings from one medical school. Acad Med 2015;90:1667-74.

27. Taylor CA, Green KE, Spruce A. Evaluation of the effect of socioeconomic status on performance in a multiple mini interview for admission to medical school. Med Teach 2015;37:59-63.

28. Terregino CA, McConnell M, Reiter HI. The effect of differential weighting of academics, experiences, and competencies measured by Multiple Mini Interview (MMI) on race and ethnicity of cohorts accepted to one Medical School. Acad Med 2015;90:1651-7.

29. Urlings-Strop LC, Stegers-Jager KM, Stijnen T. Themmen APN Academic and non-academic selection criteria in predicting medical school performance. Med Teach 2013:1-6.

30. Colquitt WL, Killian CD. Students who consider medicine but decide against it. Acad Med 1991;66:273-8.

31. Wright S. Medical school personal statements: a measure of motivation or proxy for cultural privilege? Adv Health Sci Educ Theory Pract 2015;20:1-17.

32. Greenhalgh T, Seyan K, Boynton P. "Not a university type": focus group study of social class, ethnic, and sex differences in schoo pupils' perceptions about medical school. BMJ 2004;328:1541.

33. Deci EL, Ryan R. Intrinsic motivation and self-determination in human behavior. New York and London: Plenum, 1985.

34. Ryan RM, Deci EL. Intrinsic and extrinsic motivations: classic definitions and new directions. Contemp Educ Psychol 2000;25:54-67.

35. Kusurkar RA, Ten Cate TJ, van Asperen M, et al. Motivation as an independent and a dependent variable in medical education: a review of the literature. Med Teach 2011;33:e242-e262.

36. Kusurkar RA, Ten Cate TJ, Vos CM, et al. How motivation affects academic performance: a structural equation modelling analysis. Adv Health Sci Educ Theory Pract 2013;18:57-69.

37. Artino AR, La Rochelle JS, Durning SJ. Second-year medical students' motivational beliefs, emotions, and achievement. Med Educ 2010:44:1203-12.

38. Vansteenkiste M, Zhou M, Lens W, et al. Experiences of autonomy and control among chinese learners: vitalizing or immobilizing? $J$ Educ Psychol 2005;97:468-83.

39. Sobral DT. What kind of motivation drives medical students' learning quests? Med Educ 2004;38:950-7.

40. Ryan RM, Deci EL. Self-determination theory and the facilitation of intrinsic motivation, social development, and well-being. Am Psychol 2000;55:68-78.

41. Williams GC, Saizow RB, Ryan RM. The importance of selfdetermination theory for medical educationAcad Med 1999;74:992-5.

42. Crossley ML, Mubarik A. A comparative investigation of dental and medical student's motivation towards career choice. Br Dent $J$ 2002:193:471-3.

43. Diwan V, Minj C, Chhari N, et al. Indian medical students in public and private sector medical schools: are motivations and career aspirations different? - studies from Madhya Pradesh, India. BMC Med Educ 2013;13:1.

44. Girasek E, Molnár R, Eke E, et al. The medical career choice motivations - Results from a Hungarian study. Open Med 2011;6:502-9.
45. Györffy Z, Birkás E, Sándor I. Career motivation and burnout among medical students in Hungary - could altruism be a protection factor? BMC Med Educ 2016;16:1.

46. Harrison R, Turney B, Blundell A. Motivation and insight of students considering a career in medicine. Med Teach 2003;25:669.

47. Heikkilä TJ, Hyppölä H, Vänskä J, et al. Factors important in the choice of a medical career: a finnish national study. BMC Med Educ 2015;15:169.

48. Hyppölä H, Kumpusalo E, Neittaanmäki L, et al. Becoming a doctor-was it the wrong career choice? Soc Sci Med 1998;47:1383-7.

49. McHarg J, Mattick K, Knight LV. Why people apply to medical school: implications for widening participation activities. Med Educ 2007:41:815-21.

50. McHugh SM, Corrigan MA, Sheikh A, et al. A study of the factors influencing school-going students considering medical careers. Surgeon 2011;9:191-4.

51. Molnár R, Nyári T, Hazag A, et al. Career choice motivations of medical students and some characteristics of the decision process in Hungary. Open Med 2008;3:494-502.

52. Pagnin D, De Queiroz V, De Oliveira Filho MA, et al. Burnout and career choice motivation in medical students. Med Teach 2013;35:388-94.

53. Pruthi S, Pandey R, Singh S, et al. Why does an undergraduate student choose medicine as a career. 2013.

54. Ratanawongsa N, Howell EE, Wright SM. What motivates physicians throughout their careers in medicine? Compr Ther 2006;32:210-7.

55. Skatova A, Ferguson E. Why do different people choose different university degrees? Motivation and the choice of degree. Front Psychol 2014;5.

56. Shankar N, Singh S, Gautam S, et al. Motivation and preparedness of first semester medical students for a career in medicine. 2013.

57. Freeman BK, Landry A, Trevino R, et al. Understanding the leaky pipeline: perceived barriers to pursuing a career in medicine or dentistry among underrepresented-in-medicine undergraduate students. Acad Med 2016;91:987-93.

58. Southgate E, Kelly BJ, Symonds IM. Disadvantage and the 'capacity to aspire' to medical school. Med Educ 2015;49:73-83.

59. McManus IC, Livingston G, Katona C. The attractions of medicine: the generic motivations of medical school applicants in relation to demography, personality and achievement. BMC Med Educ 2006;6:11.

60. Kuper A, Reeves S, Levinson W. An introduction to reading and appraising qualitative research. BMJ 2008;337:a288-7.

61. Mertens DM. Research and evaluation in education and psychology: integrating diversity with quantitative, qualitative, and mixed methods. Sage Publications 2014.

62. Lincoln YS, Guba EG. The only generalization is: there is no generalization. Case study method 2000:27-44.

63. Tong A, Sainsbury P, Craig J. Consolidated criteria for reporting qualitative research (COREQ): a 32-item checklist for interviews and focus groups. Int J Qual Health Care 2007;19:349-57.

64. King N. Doing template analysis. In: Gillian Symon CC, ed. Qualitative organizational research: core methods and current challenges. London: SAGE, 2012:426-50.

65. Elo $\mathrm{S}$, Kyngäs $\mathrm{H}$. The qualitative content analysis process. $J \mathrm{Adv}$ Nurs 2008;62:107-15.

66. Girotti JA, Park YS, Tekian A. Ensuring a fair and equitable selection of students to serve society's health care needs. Med Educ 2015;49:84-92.

67. Grbic D, Jones DJ, Case ST. The role of socioeconomic status in medical school admissions: validation of a socioeconomic indicator for use in medical school admissions. Acad Med 2015;90:953-60.

68. Vansteenkiste M, Mouratidis A. Emerging trends and future directions for the field of motivation psychology: a special issue in honor of Prof. Dr. Willy Lens. Psychol Belg 2016;56:317-41.

69. Frenk J, Chen L, Bhutta ZA, et al. Health professionals for a new century: transforming education to strengthen health systems in an interdependent world. The Lancet 2010;376:1923-58. 